\title{
El Anatomista Español que se Atrevió a Rectificar a Vesalio: Juan Valverde de Amusco
}

\author{
The Spanish Anatomist who Dared to Rectify Vesalius: Juan Valverde de Amusco
}

\begin{abstract}
Alfredo Moreno-Egea*
MORENO-EGEA, A. El anatomista español que se atrevió a rectificar a Vesalio: Juan Valverde de Amusco. Int. J. Morphol., 34(3):10091016, 2016.

RESUMEN: Las aportaciones científicas de los anatomistas españoles del renacimiento son muy poco conocidas a nivel internacional, sin embargo, fueron clave para comprender la anatomía actual, en especial la obra anatómica de Juan Valverde de Amusco, "el Vesalio español". Este trabajo tiene como objetivo mostrar que su obra anatómica es original, y que supuso un hito histórico para la ciencia y la lengua castellana. Frente a la Fábrica de Vesalio, escrita en latín académico y difícil de comprender, se sitúa la obra de Valverde como el primer manual moderno de anatomía, escrita en castellano, preciso y sencillo, con una difusión por Europa muy superior, que facilitó el conocimiento profesional a médicos, cirujanos y artistas. La obra de Juan Valverde debe considerarse como original, en base a su contribución: (1) a la utilización del método científico en la anatomía, (2) al desarrollo del español como idioma científico demostrando que este idioma es muy útil y conveniente para expresar los conocimientos médicos y llegar a un mayor número de profesionales, (3) por introducir en el lenguaje científico las ideas de claridad, sencillez y rigor.
\end{abstract}

PALABRAS CLAVE: Anatomía; Historia; Vesalio; Juan Valverde.

\section{INTRODUCCIÓN}

Durante más de 12 siglos la única anatomía conocida fue la obra incuestionable de Galeno. Sus conocimientos estaban basados en la disección de animales, por lo que su obra presentaba múltiples errores, pero a pesar de ello, fueron asumidos como si de una verdad absoluta se tratara, y que nadie se atrevió a cuestionar. A partir del siglo XIII fueron apareciendo pequeños cambios de mentalidad que hicieron posible los grandes avances que vendrían con el Renacimiento, y el más destacado para nosotros fue sin duda la posibilidad de realizar disecciones humanas. En 1230, Federico II, Emperador de Alemania y Rey de las Dos Sicilias, impone la condición de haber estudiado, al menos un año de Anatomía sobre cuerpos humanos para poder practicar la Medicina. Este hecho fue el primer impulso que favoreció el estudio de la naturaleza, y el primer anatomista en utilizar la disección como base de su conocimiento para construir su obra fue Mondino de Liucci (1250-1326). Es decir, en su obra, Anatomía Mundini a capite usque ad pedes, publicada en 1478, incluye las primeras láminas anatómicas de la historia realizadas bajo una metodología experimental.
En Francia, Louis de Anjou en 1376, concedió permiso para disecar cada año el cadáver de un ajusticiado, y Carlos VI en 1396, impone como obligación a los gobernantes de Montpellier entregar a la Escuela de Medicina el cadáver de un condenado a muerte cada año. En Italia la disección se inicia en 1430 por Marc Fuscari. En España, se inicia en 1322 en el Monasterio de Guadalupe, donde los monjes obtuvieron un Privilegio del Pontificado para realizar disecciones a los cadáveres de aquellos peregrinos que allí fallecieran y se pudiese investigar la causa de su muerte. Posteriormente en Aragón, en 1391, el rey Juan II dictó un Privilegio a la Universidad de Lérida ordenando a los Tribunales de Justicia enviar a dicha Universidad los cadáveres de los ajusticiados para que se hiciera Anatomía, y en 1488, fue en Zaragoza donde Fernando el Católico concedió un privilegio a sus médicos autorizándoles a realizar disecciones de cadáveres humanos (Alberti, 1948).

Desde el siglo XIV se difunde por Europa una nueva corriente individualista que convierte al hombre en el centro de todo interés, y una nueva visión crítica que hace que 
el conocimiento del cuerpo humano mediante la disección llegue a ser la disciplina básica de la medicina. Estos hechos potenciaron el desarrollo de la anatomía, y culminaron con la publicación de la obra de Vesalio. Esta obra representó el inicio de la anatomía moderna y fue utilizada como base para cualquier avance posterior.

\section{BIOGRAFÍA}

Juan Valverde nació en Amusco, Palencia, en 1525. Posiblemente iniciara su carrera en la Cofradía-hospital de San Millán de los Palmeros, en la misma villa de Amusco. En torno a 1538 se fue a Valladolid para estudiar Filosofía y Humanidades, en cuya Universidad se gradúo. En 1542 decide marchar a Italia, con 17 años de edad, para proseguir su formación científica. Esta decisión debió responder a las restricciones existentes en España para realizar disecciones anatómicas y a la carencia de grandes hombres que entendieran y enseñaran anatomía. Por aquel entonces, Italia disponía de las mejores posibilidades para la formación, y las disecciones humanas no eran mal vistas. Parece pues que la vocación por la anatomía debió de ser el motor que le impulsó a recorrer Europa en busca de buenos maestros, y eligió Padua como su primer destino. Apenas dos años antes, los valencianos Pedro Jimeno y Luis Collado hicieron el mismo viaje para completar su formación asistiendo directamente a las clases del maestro Vesalio y posteriormente, Pedro Jimeno trasladó su anatomía a su Cátedra en la Universidad de Valencia, y finalmente a la de Alcalá de Henares, dejando su lugar en Valencia a Collado. Valverde sin embargo, llegó a Padua y descubrió a Realdo Colombo, estudiante de último año de Vesalio, figura que se convertiría en su maestro de por vida. En 1543, el Emperador Carlos V pidió a Vesalio que se trasladase a su corte y este abandonó su puesto docente, sucediéndole en la cátedra Colombo durante 3 cursos completos, donde Valverde se convirtió en su fiel ayudante-disector (Fernández-Ruiz, 1958; 1959).

En 1545, Cosimo de Medici pidió a Colombo que se traslade a Pisa y Valverde le acompañó inscribiéndose en la Universidad Artista de Pisa. Fue al mismo tiempo ayudante de la cátedra y alumno, y ambos realizaron múltiples disecciones, en las cuales podrían haber descubierto la circulación de la sangre pero no lo publicaron por las posibles consecuencias con el Santo Oficio (Barón Fernández, 1970). Pero, en 1556 Valverde lo comenta en su obra respetando la autoria del descubrimiento a su maestro Colombo, quien si lo publica en 1559, en su obra De Re anatomica (Venecia, Nicolai Beuilacquae).

En 1548, el Papa Paolo III llama a Colombo para pedirle que se desplace a Roma para regentar la cátedra de ana- tomía. Como siempre, Valverde le siguió, y fue en esta ciudad donde consiguió alcanzar su grado profesional y el cenit de su carrera. Su primer patrono fue Girolamo Verallo, bajo su protección pública su primera obra titulada De animi et corporis sanitate tienda libellus (1553). En Roma estudió y trabajó con Bartolomeo Eustachio. Estuvo vinculado a su maestro Colombo en la Universidad (como docente) y en el Hospital del Espíritu Santo, como clínico desde 1553, ampliando sus conocimientos en anatomía y cirugía. Desde la cátedra tuvo la oportunidad de formar médicos para ser cirujanos, y desde el hospital formar a cirujanos en el arte de tratar úlceras, fracturas y luxaciones. Su segundo protector fue el Cardenal Juan Álvarez de Toledo, arzobispo de Santiago e inquisidor general. Su libro de anatomía Historia de la composición del cuerpo humano, fue una petición que éste le hizo. En 1555 fue propuesto como médico de la familia Pontificia, puesto que parece no consiguió. El 31 de julio de 1556 pudo formar parte del equipo de médicos que realizaron la autopsia y embalsamaron a San Ignacio de Loyola, dirigido por su maestro Colombo. También estuvo presente en la autopsia del Cardenal Cibo (Navarro, 1927).

En 1558 hizo un viaje de visita a su villa natal, como portador de la Bula concedida por Paulo IV a la Iglesia de Nuestra Señora de Amusco. Aunque estaba orgulloso de su tierra no regreso para ejercer la medicina por el ambiente conservador que reinaba en las universidades. Algunos historiadores valoran este hecho como una penitencia por su pasado (Andretta, 2009). Se cuenta por Palencia que cometió algún error con un paciente y tuvo una reacción violenta con un familiar, motivo por el que tuvo que huir de su villa natal. En Italia coincidió con los anatomistas españoles Rodríguez de Guevara, Pedro Jimeno y Bernardino Montaña de Monserrate. En 1559, Colombo muere y sus hijos, Lázaro y Febo, publican su obra póstuma De re anatómica. La muerte de su maestro y amigo debió de afectarle mucho, ya que a él debía su formación y su situación social. No se encuentran noticias después de este hecho, hasta que muere en Roma en 1587. Al día de hoy, no sabemos donde fue sepultado (Riera Palmero, 1986).

\section{OBRA ANATÓMICA}

Su primer trabajo, De animi et corporis sanitate tuenda libellus, un tratado sobre higiene, alimentación y buenas costumbres, se publicó en París en 1552, dedicado al cardenal Girolamo Verallo. Su segundo y definitivo trabajo fue la Historia de la composición del cuerpo humano, tratado anatómico cuya primera edición se publicó en Roma en 1556, en castellano, por los editores Antonio de Salamanca y Antonio Lafreri. 


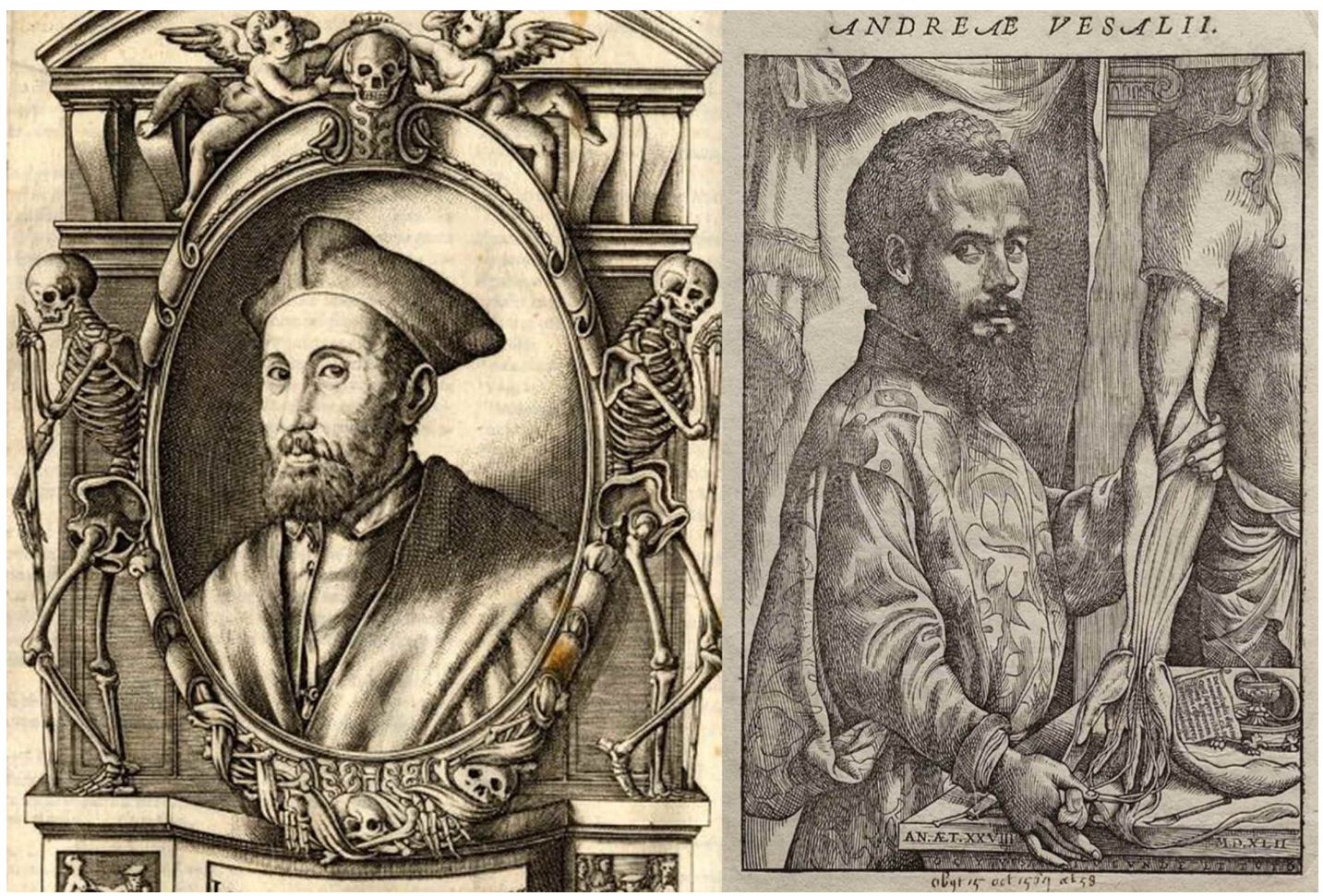

Fig. 1. Retratos de Juan Valverde y de Andrés Vesalio.

El permiso de impresión de Paolo IV y el estar dedicada a un Arzobispo, nos indican que la iglesia no se opuso a su divulgación, más bien la estimuló y protegió. Fue uno de los textos sobre anatomía más profusamente leídos y editados en todo el Renacimiento. La mayor parte de las 42 láminas calcográficas son copias mejoradas del De humani corporis fabrica de 1543 de Andrés Vesalio, cosa que el propio Valverde reconoció en la dedicatoria del libro, a pesar de lo cual Vesalio, molesto por este hecho, le acusó de plagio y de no haber hecho nunca una disección anatómica por sí mismo (Huard \& ImbaultHuart, 1980) (Fig. 1).

\section{Láminas anatómicas}

Las ilustraciones representaron el mayor reclamo de su obra, mostrando una gran inspiración artística y objetividad científica. Los dibujos unen ciencia y arte, característica del renacimiento, y sirvieron como hito en la historia de la enseñanza médica al emplear una metodología basada principalmente en las imágenes. Han sido atribuidas al pintor florentino Gaspar Becerra (escuela de Alonso Berruguete y de Miquel Ángel), al español Pedro de Rubiales, elogiado por el propio Valverde, o al grabador Nicolás Béatrizet, cuyas iniciales "NB" aparecen en dos estampas y en el retrato incorporado en la edición de 1589. Pero todavía hoy se mantiene la controversia de porque el autor oculto el nombre del dibujante (Carlino, 2002). Las ilustraciones indican que Valverde tenía un verdadero diseño propio para su obra. La originalidad del autor se advierte desde la portada del libro, las figuras con cambios estéticos, de fondo y de situación, con la representación de elementos clásicos (como del Santo Bartolomé, el Apolo de Belvedere o la diosa griega Afrodita) y la presencia de una pequeña iconografía diseminada por todo el tratado (Meyer \& Wirt, 1943). Algunos ejemplos de su originalidad son:

- Libro I: el esqueleto agarra un bastón,(Fig. 2b) no una pala de enterrador como en la figura de Vesalio (Fig. 2a). De forma simbólica, este hecho representa el palo de Efrain y José, dos naciones de Israel unidas bajo un solo gobierno divino. El palo significa la unión espiritual de todas las naciones europeas.

- Libro II: en el Hombre desollado representa al Santo Bartolomé, basado en el Miquel Ángel del juicio final de la Capilla Sixtina (Fig. 3). En esta imágen el modelo viene completamente de lado para representar perfectamente los músculos de la cara, y la pierna esta alzada para que se vean mejor los músculos en movimiento. 


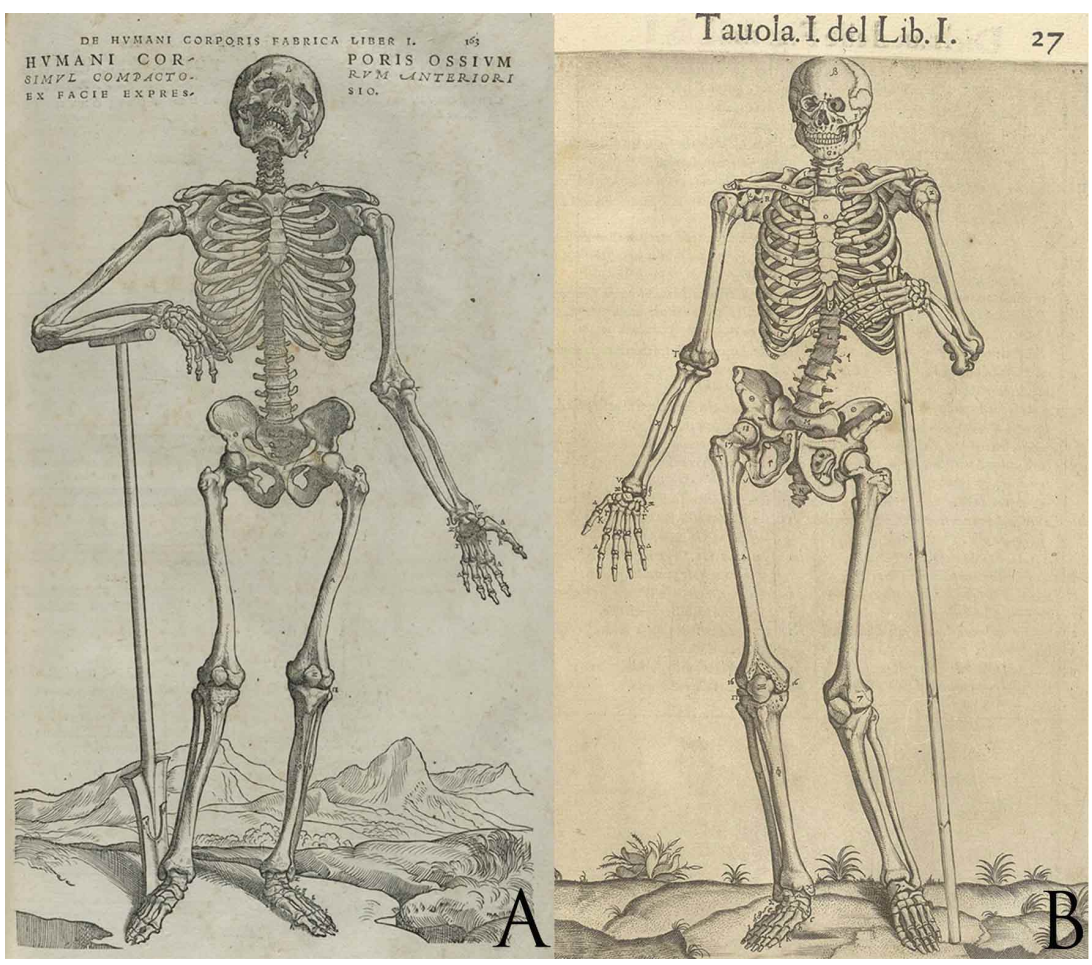

Fig. 2. Lámina del esqueleto óseo. Comparación entre la de (A). Andrés Vesalio y de Juan Valverde (B). Este aporta un cambio estético (fondo crudo sin paisaje y figura con más movimiento), teológico (cambia la pala por el bastón de Josué) y científico (rectifica las curvas del fémur, clavículas, etc.).

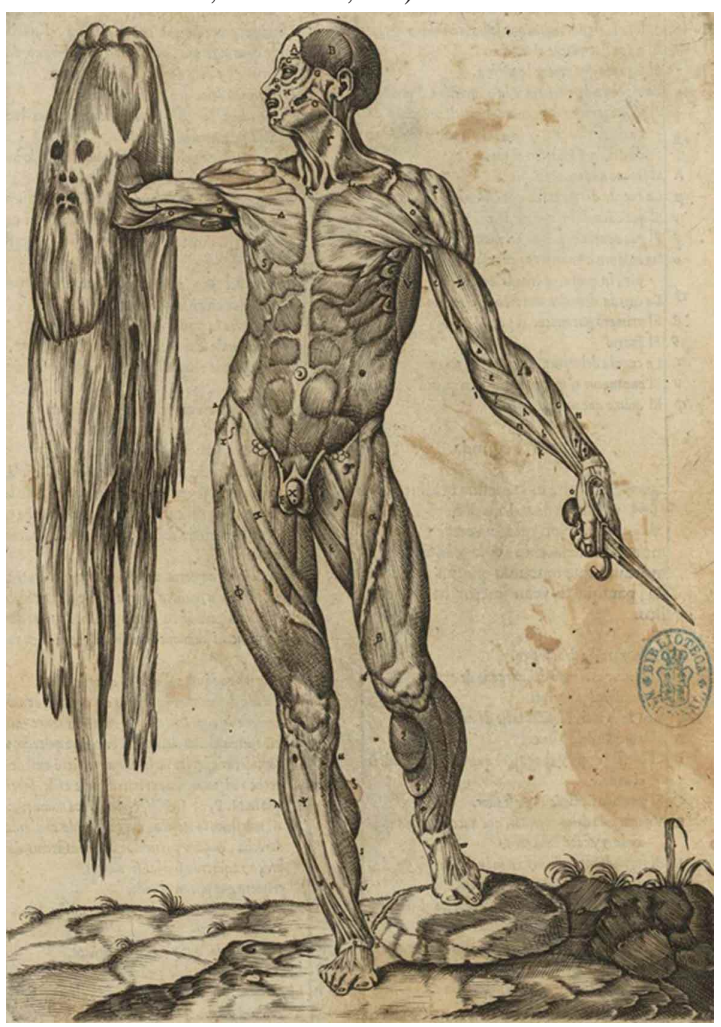

Fig. 3. Lámina del llamado Hombre Desollado de Valverde.
- Libro III: inspirada en la obra de Apolonio conocida como el torso del Belvedere. En esta imágen las vísceras abdominales se muestran dentro de la coraza de un soldado romano, no dentro del palio de un comandante como utiliza Vesalio. Representa la diosa griega Afrodita en actitud sorprendida al salir del mar. Es una copia de la Opulenza situada en el Palacio de la Cancilleria

- Tabla I Libro VI: representa el árbol venoso del cuerpo humano en un hombre desollado. Lo curioso es la pose que adopta como simulando un paso de baile o danza macabra. La figura consigue aparentar movimiento y dar vida al cadáver humano (Fig. 5).

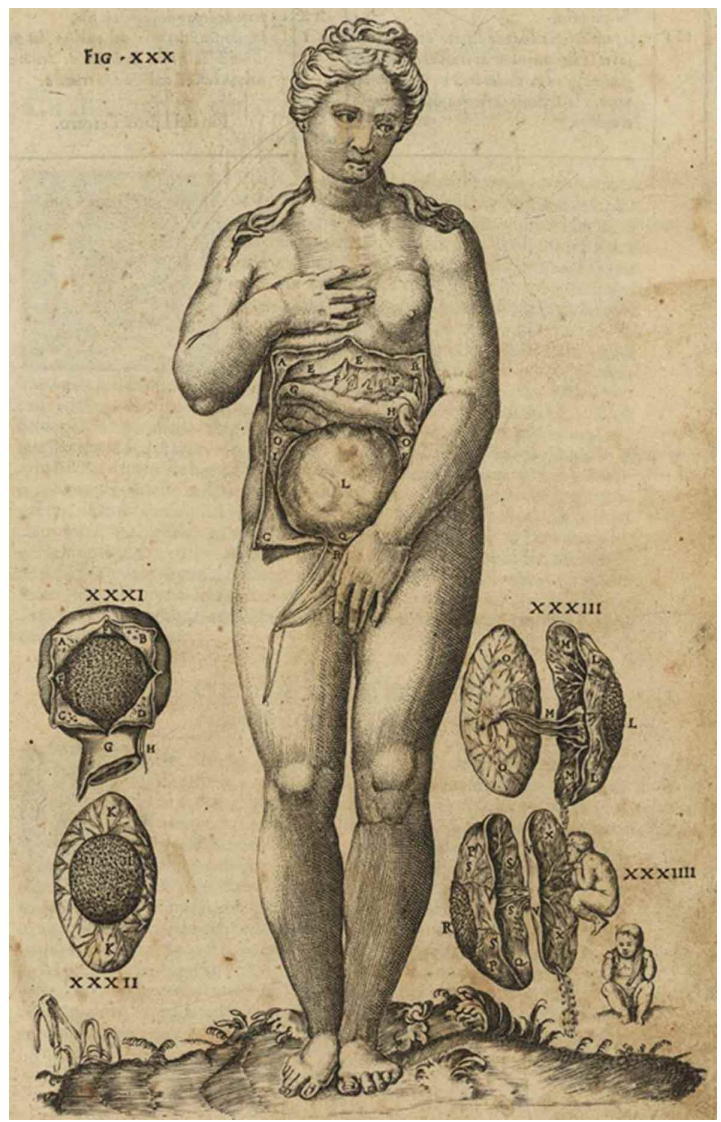

Fig. 4. La figura de la mujer gestante con la pared abdominal $y$ el peritoneo abierto para mostrar el útero grávido. Incluye una figura del feto con la placenta, a diferencia de la de Vesalio que corresponde al de una perra. Representa la diosa griega Afrodita como distraída o ausente. 


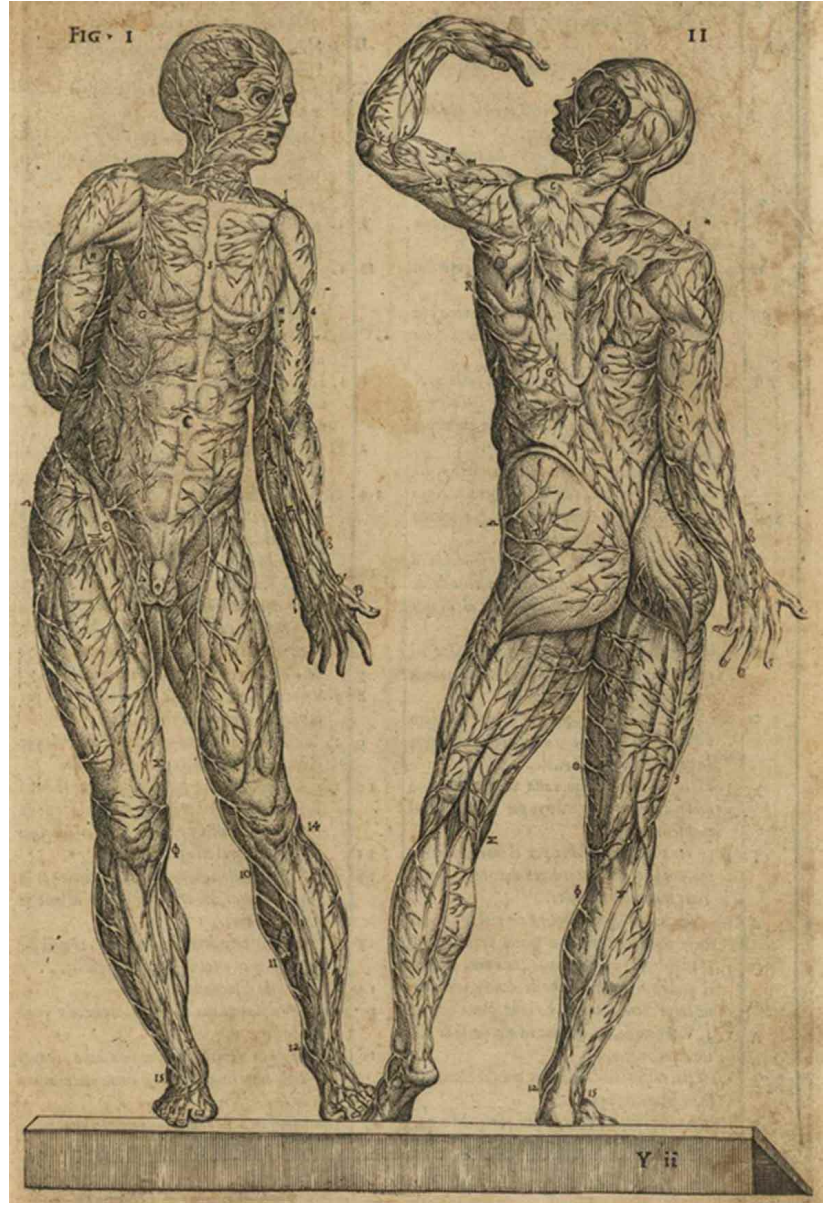

Fig. 5. Representa el árbol venoso del cuerpo humano en un hombre desollado.

El texto se divide en 7 libros con una descripción del organismo estática y arquitectural de forma descendente, comenzando el diseño de su "fabrica" por los huesos y músculos (elementos que forjan el alimento, la sangre y los espíritus) que cubren los tres apartamentos de su "Casa Real", abdomen, pecho y cabeza, para terminar con los vasos y nervios que constituyen los canales por los que discurren y distribuyen la vida. Valverde modifica el orden de los libros de Vesalio (huesos, músculos, vasos, nervios, abdomen, pecho y cabeza) obedeciendo a su personal visión de concebir el conocimiento anatómico. Su Anatomía es ligera, sencilla, intentando recrear al hombre como si de una fortaleza se tratara. Todas las aportaciones de su texto se apoyan directamente en su experiencia clínica y a través de sus autopsias, lo que el mismo autor se encarga de mencionar a lo largo de toda su obra (López Piñero, 1983).
El texto va más allá de lo puramente científico, porque aporta un nuevo valor de tipo lingüístico. Lobera de Ávila fue el primer anatomista que escribió en lengua romance parte de su obra, concretamente el sueño, pero no su texto de anatomía. Bernardino Montaña, en 1551, fue el primer anatomista español que escribió su Libro de la anatomía del hombre totalmente en lengua romance. A diferencia de la Fabrica que apenas podía ser comprendida, la obra de Valverde, escrita en castellano vulgar, de forma sencilla y breve, con las láminas situadas al final de cada capítulo, facilito su difusión, especialmente entre el estrato más humilde de la Medicina de la época: cirujanos y sangradores. Por ello, se convierte en precursor de una dignificación de la profesión quirúrgica. Valverde inicia el uso del castellano como lengua de ciencia creando un lenguaje anatómico castellano hasta entonces inexistente, expresa sus conceptos anatómicos con términos extraídos de la cultura popular, con palabras nacionales que la gente usaba, creando una nueva nomenclatura científica española (Valle-Inclan, 1949).

\section{APORTACIONES NUEVAS}

\section{Descripciones del Libro De humani Corporis fabrica de Vesalio}

- Libro I: descripción del hueso palatino (p.7), maxilar (p.9), vértebras lumbares (p.12), y de la extremo superior del húmero (p.16).

- Libro II: menciona los músculos frontales (p.32), las alas de la nariz (p.33), músculos de la lengua (p.35) y de la palma de la mano (p.46).

- Describe el peritoneo parietal (p.60).

- Describe los nervios craneales (p.99).

- Utiliza por primera vez la palabra de origen islámico duramadre (p.80).

- Representa por primera vez el estribo, hueso del oído medio descrito un año antes por el Valenciano Luis Collado.

\section{- Rectificaciones anatómicas del libro de humani corporis la Fabrica}

- Huesos: rectifica la descripción de la articulación de los huesos de la mano (p.21), del pie (p.26-27) y la incurvación de la clavícula.

- Músculos: corrige la descripción general explicando que todo músculo debe tener una vena, arteria y nervio, aunque no se perciban (p.31), el número de músculos intercostales (p.42), el tamaño e inserción del músculo escaleno anterior, y la inserción de los músculos rectos abdominales que Vesalio 


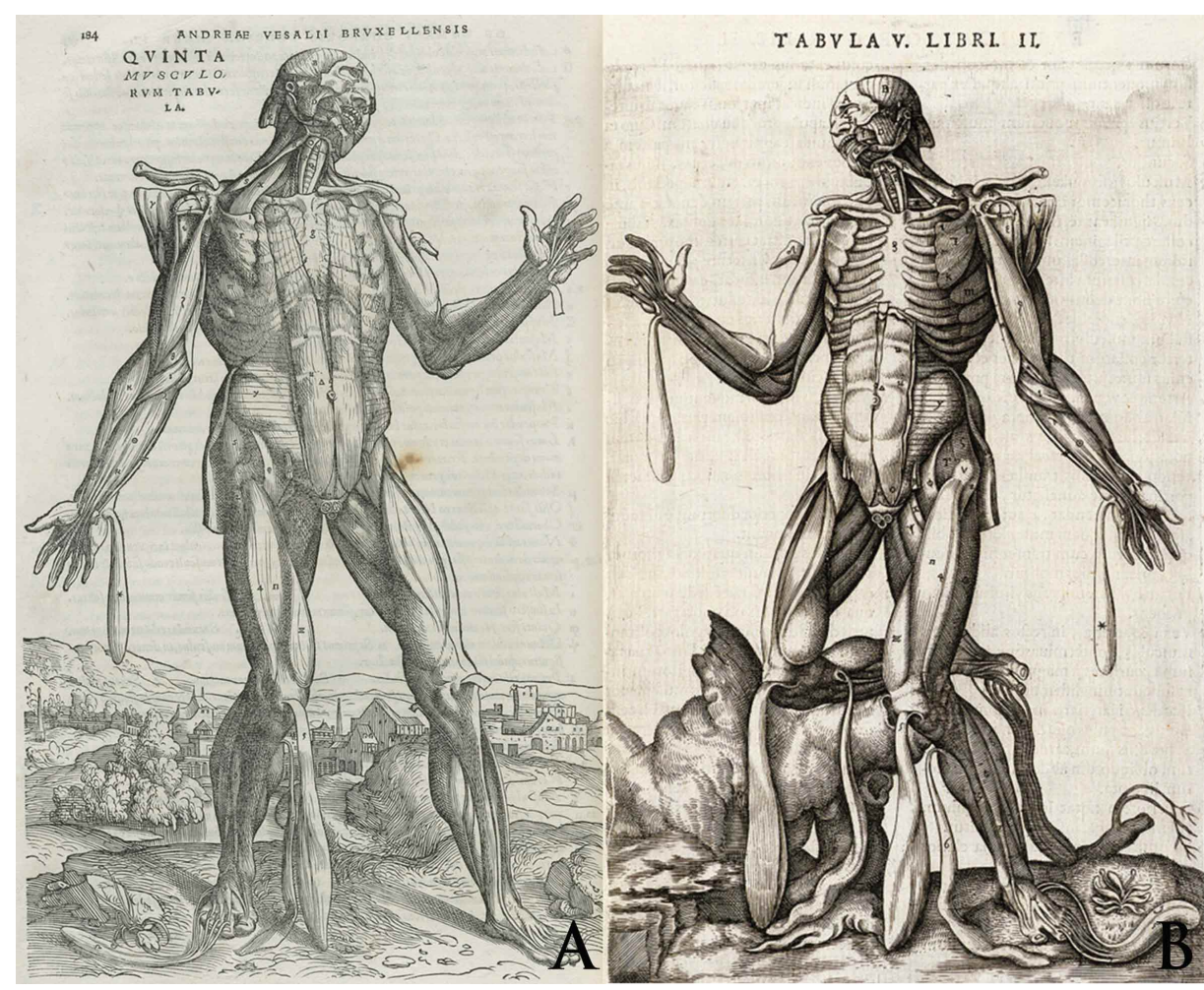

Fig. 6. Lámina de la musculatura anterior. (A). Andrés de Vesalio, (B) Juan Valverde. Se aprecia la rectificación del músculo recto anterior de la pared abdominal, y del tamaño del músculo escaleno.
- Describe de forma precisa la circulación de la sangre desde el ventrículo derecho del corazón al izquierdo a través de los pulmones, corroborando lo descubierto originariamente por Ibn an Nafis, en 1255. No existen los orificios septales interventriculares como pensaban Galeno y Vesalio.

\section{¿Debe considerarse un plagio la obra de Juan Valverde?}

Vesalio arremetió duramente contra Valverde acusándole de plagio y de no haber hecho nunca una disección. En su obra Anatomicarum Gabrielis Fallopii observationum examen (1564), dice textualmente: "El que nunca usó las manos para cortar ni para la medicina, ni para la vida, es un ignorante de las principales disciplinas. Y practicó el oficio de traductor a la lengua hispana en esta los hace ascender por el pecho hasta insertarlos en las clavículas (p.53-56) (Fig. 6).

- Expresa el carácter anormal de las adherencias pleurales, que Vesalio había considerado como ligamentos pleurales (p.74).

- Morfología ocular: el número de los músculos oculomotores, 5 (p.32), no hay uno que haga intersección con el nervio óptico, el humor acuoso es muy escaso, apenas 6-7 gotas (p.82), representa el músculo ciliar, el elevador del párpado superior, la polea de deslizamiento del músculo oblicuo mayor y el aparato lacrimal.

- Sistema nervioso: verifica que sólo hay 3 ventrículos cerebrales (para Galeno 2, y para Vesalio 4), y niega la existencia del plexo retiforme (para Galeno, Avicenas y Mondino, es una estructura formada por un conjunto de hilos muy finos y entrelazados que se extienden de la base del cerebro hasta penetrar por el orificio de la meninge) (Martín-Araguz et al., 2001).

- Venas y arterias: corrige las ramas del arco aórtico y modifica el trayecto de las venas y arterias del brazo (p.87), de la cabeza (p.96), del ombligo (p.92) y de los testículos (p.89). nuestra arte solamente a causa de la torpe ganancia". Vesalio se enfrentó no solo a Valverde, también a Colombo y a cualquier otro anatomista que mencionara errores en su obra. La consideración de plagio en el caso de Valverde sólo representa una gran ignorancia respecto de su obra, por las novedades tanto formales como científicas que aporta, como ya hemos analizado.

Valverde al principio de su obra, reconoce abiertamente de forma humilde el motivo de usar las láminas de Vesalio como punto de partida para su trabajo. Pero no se limita a copiarlas, como si hizo el impresor inglés Thomas Geminus en el Epitome (1545), sino que las toma como modelo para mejorar los detalles morfológicos, introducir los cambios científicos advertidos en sus propias disecciones, e incluir cambios estéticos y teológicos de gran interés. Las modificaciones que realiza tienen un fin, permiten ver mejor los detalles anatómicos y rectificar los errores. El nuevo carácter estético se puede ver en las figuras basadas en modelos clásicos y en el paisaje elegido como fondo. A diferencia de Vesalio que endulzaba las figuras con un fondo de paisaje real, Valverde deja que nos fijemos en la figura y elimina cualquier fondo llamativo dejando sólo unas rocas, tierra o troncos de árbol. Su interés es la anatomía, mostrar al hombre como el centro de todo. Lo que hace es usar el moderno método científico de 
Tabla I. Datos históricos comparativos entre Andrés Vesalio y Juan Valverde.

\begin{tabular}{lll}
\hline & Andres Vesalio & Juan Valverde \\
\hline \multirow{2}{*}{ Origen } & $\mathbf{( 1 5 1 4 - 1 5 6 4 )}$ & $\mathbf{( 1 5 2 5 - 1 5 8 7 )}$ \\
Formación & Belgica (Bruselas) & Español (Palencia) \\
Obra & Lovaina y Paris & Universidad de Valladolid \\
& 1543: De humani corporis fabrica libri & 1556: Historia de la composición del cuerpo \\
Madurez & septem & humano \\
Dedicada & Emperador Carlos V & 31 años \\
Idioma & Latín académico & Juan Álvarez de Toledo \\
Páginas & 824 & Castellano (Romance) \\
Publicación & Basilea & 154 \\
Láminas & Xilográficas (en taco de madera) 73. & Roma \\
Editor & Johannes Oporinus & Calcográficas (en cobre) 15 originales \\
Ilustrador & Jan Stefan van Kalkar & Antonio Martínez de Salamanca \\
& (discípulo de Tiziano) & Gaspar Becerra i? \\
Fondo & Vistas de Abano Terme & Nicolas Béatrizet \\
Simbolismo & Pobre & Tierras áridas, rocas, vegetación pobre (sin un lugar \\
Idiomas & Latín (al Español en 1997) & concreto) \\
Difusión & Muy limitada & Rico (gran carga teológica) \\
Curiosidad & 1564: Autopsia a un noble vivo sincopado. & Español, Latín, Italiano, Griego y Flamenco \\
& Es condenado a la hoguera y Felipe II & Muy amplia \\
& cambia la sentencia por una peregrinación a de tratamiento y lentitud de actuación. \\
& Tierra Santa. & Consigue una bula Papal para la Cofradía-hospital \\
& de San Millán en su villa natal. \\
\hline
\end{tabular}

comparación de resultados para mostrarnos los errores cometidos por Vesalio. Gracias a su rigor empírico hizo avanzar la anatomía al rango de verdadera ciencia. Luego los comentarios de Desgenettes, en su Historia de la Anatomía y de la Cirujía, de que "la obra de Valverde es casi igual a la de Vesalio, con la diferencia de que añadió algunas notas poco esenciales e hizo láminas sin aumentar su exactitud..." solo indican un escandaloso atrevimiento del Francés al opinar sin haber visto el libro antes. Como bien dice Morejón: "lo que dice es soñado” (Morejón, 1842).

El aspecto de que se publicara en español debe considerarse también como un aspecto de originalidad, ya que no solo mejoró el conocimiento científico de los profesionales españoles, sino que confirmaba la tendencia renacentista a usar la propia lengua natural frente al latín, como vehículo de la cultura médica. Su objetivo era dirigirse a los cirujanos españoles, que desconocían el latín y no podían adquirir suficientes conocimientos anatómicos para desarrollar con seguridad su formación y ejercicio profesional. Valverde debe considerarse como un firme defensor de la lengua castellana en el campo de la ciencia médica. Después, la obra fue traducida al italiano, y otros idiomas, lo cual indica que fue muy leída en Europa durante los siglos XVI y XVII, e incluso más tarde porque en el siglo XVIII apareció una traducción al griego. Este camino permitió a Valverde hacer llegar el saber anatómico, desde las academias y las universidades, a los despachos de cirujanos, sangradores y dentistas, disminuyendo las enormes diferencias que existían entre los profesionales de la curación. A nuestro entender, su vida y su obra, establecieron un puente entre la academia y el ejercicio real de la medicina, que facilitaría el avance posterior de la cirugía como ciencia (Hernández, 2014).

\section{CONCLUSIONES}

La obra de Juan Valverde debe considerarse, a nuestro juicio como original, en base a su contribución: (1) a la utilización del método científico en la anatomía, (2) al desarrollo del español como idioma científico demostrando que este idioma es muy útil y conveniente para expresar los conocimientos médicos y llegar a un mayor número de profesionales, (3) por introducir en el lenguaje científico las ideas de claridad, sencillez y rigor, mediante la publicación del primer manual moderno de anatomía española (por el tamaño de su obra, uso de láminas y de expresiones populares). 


\section{AGRADECIMIENTOS}

Al Departamento de Anatomía Humana. Facultad de Medicina, Universidad Católica San Antonio, Murcia España.

MORENO-EGEA, A. The Spanish anatomist who dared to rectify Vesalius: Juan Valverde de Amusco. Int. J. Morphol., 34(3):10091016, 2016.

SUMMARY: The scientific contributions of Spanish Renaissance anatomists are little known internationally, but were the key to understanding current anatomy, especially the anatomical work of Juan Valverde de Amusco, "the Spanish Vesalius". This study shows that his anatomical work is original, and that it was a milestone for science and for the Spanish language. Located across from the Vesalius factory, where the Latin writing is academic and difficult to understand, stands the work of Valverde as the very first modern anatomy manual, written in simple and accurate Castilian. It was disseminated extensively throughout Europe, which facilitated knowledge for professional physicians, surgeons and artists. The anatomy of Juan Valverde should be considered as original, based on its contribution: (1) the use of scientific method in anatomy, (2) the development of Spanish as a scientific language, proving that this language is useful, convenient for conveying medical knowledge, and contributes in reaching greater numbers of professionals, (3) to introduce in scientific language the ideas of clarity, simplicity and rigor.

\section{Vesalio.}

KEY WORDS: Anatomy; History; Juan Valverde;

\section{REFERENCIAS BIBLIOGRAFICAS}

Alberti, L. La Anatomía y los Anatomistas Españoles del Renacimiento. Madrid, Consejo Superior de Investigaciones Científicas, 1948.

Andretta, E. Juan Valverde, or Building a "Spanish Anatomy" in 16th Century Rome. Florencia, European University Institute, 2009.

Barón Fernández, J. Miquel Servet: Su Vida y Su Obra. Madrid, Editorial Espasa Calpe, 1970. pp.194-5.

Carlino, A. Tre Piste per l'Anatomia di Juan Valverde: Logiche d'Edizione, Solidarietà Nazionali e Cultura Artistica a Roma nel Rinascimiento. En: Mélanges del Ecole Française de Rome - Italie et Méditerranée. Rome, École Francaise de Rome, 2002

Fernández-Ruiz, C. Estudio Biográfico sobre el Doctor D. Juan Valverde de Amusco, Gran Anatómico del Siglo XVI, y su Obra. Zaragoza, Octavio y Félez, 1958.
Fernández Ruiz, C. Historia de la Medicina Palentina. Palencia, Publicaciones de la Institución Tello Téllez de Meneses $\mathrm{N}^{\mathrm{o}}$ 20, 1959. pp.73-112.

Geminus, T. Compendiosa Totius Anatomie Delineatio. Londini, Ioani Herfordie, 1545.

Hernández, J. M. La Idea de Hombre de Juan Valverde de Amusco. Tesis doctoral. Madrid, Universidad Complutense, 2014.

Hernández Morejón, A. Historia Bibliográfica de la Medicina Española. Obra Póstuma de Don Antonio Hernández Morejón. Madrid, Ed. Viuda de Jordán e hijos, 1842.

Huard, P \& Imbault-Huart, M. J. Andrés Vesalio. Iconografía Anatómica. Fabrica, Epitome, Tabulae Sex. Barcelona, Temis, 1980. pp. 240-5.

López Piñero, J. M.; Glick, T. F.; Navarro Brótons, V. \& Portela, E. Diccionario Histórico de la Ciencia Moderna en España. Vol. II. Barcelona, Península, 1983. pp. 394-6.

Martín-Araguz, A.; Bustamante-Martínez, C.; Toledo-León, D.; López-Gómez, M. \& Moreno-Martínez, J. M. La neuroanatomía de Juan Valverde de Amusco y la medicina renacentista española. Rev. Neurol., 32(8):788-97, 2001.

Meyer, A. W. \& Wirt, S. K. The Amuscan illustrations. Bull. Hist. Med., 14:667-87, 1943.

Navarro, R. El Doctor Juan de Valverde de Amusco. En: Boletin del Colegio de Médicos de la Provincia de Palencia, Números 209 y 210. Palencia, Imp. y Lib. de Abundio Z. Menéndez, 1927. pp. 6.

Riera Palmero, J. Juan Valverde de Amusco y la Medicina del Renacimiento. Valladolid, Universidad de Valladolid, 1986.

Valle-Inclán, C. El léxico anatómico de Bernardino Montaña de Monserrate y de Juan Valverde. Arch. Iberoam. Hist. Med., $1: 121-88,1949$.

Correspondencia:

Dr. A. Moreno Egea

Avda Primo de Rivera $7,5^{\circ} \mathrm{D}$,

3008. Murcia

ESPAÑA

Teléfono: 639662113

E-mail: morenoegeaalfredo@gmail.com
Recibido : 24-01-2016 Aceptado: 05-07-2016 